OPEN ACCESS

Edited by:

Elena Adinolfi,

University of Ferrara,

Italy

Reviewed by: Luca Antonioli,

University of Pisa, Italy

Ronald Sluyter,

University of Wollongong,

Australia

*Correspondence:

Carla Cicala

cicala@unina.it

Specialty section:

This article was submitted to

Experimental Pharmacology and

Drug Discovery,

a section of the journal

Frontiers in Pharmacology

Received: 08 April 2019

Accepted: 17 June 2019

Published: 11 July 2019

Citation:

Caiazzo E, Morello S, Carnuccio R, lalenti A and Cicala C (2019)

The Ecto-5'-Nucleotidase/CD73 Inhibitor, $\alpha, \beta$-Methylene Adenosine

5'-Diphosphate, Exacerbates Carrageenan-Induced Pleurisy in Rat.

Front. Pharmacol. 10:775.

doi: 10.3389/fphar.2019.00775

\section{The Ecto-5'-Nucleotidase/CD73} Inhibitor, $\alpha, \beta-M e t h y l e n e ~ A d e n o s i n e$ 5'-Diphosphate, Exacerbates Carrageenan-Induced Pleurisy in Rat

\author{
Elisabetta Caiazzo ${ }^{1}$, Silvana Morello ${ }^{2}$, Rosa Carnuccio ${ }^{1}$, Armando lalenti ${ }^{1}$ \\ and Carla Cicala ${ }^{1 *}$ \\ ${ }^{1}$ Department of Pharmacy, School of Medicine, University of Naples Federico II, Via Domenico Montesano 49, Naples, Italy, \\ ${ }^{2}$ Department of Pharmacy, University of Salerno, Via Giovanni Paolo II 132, Fisciano, SA, Italy
}

The ecto-5'-nucleotidase (ecto-5'NT/CD73) represents a crucial enzyme for endogenous adenosine generation. Several findings have shown that CD73 plays an important role in regulating vascular permeability and immune cell function. Adenosine $5^{\prime}-(\alpha, \beta-$ methylene)diphosphate (APCP) is a CD73 inhibitor, widely used as pharmacological tool to investigate the role of CD73/adenosine pathway in several in vitro and in vivo models, although it has been also shown to inhibit other ectoenzymes involved in adenosinergic pathway. Here, we evaluated the effect of APCP in the development of inflammation in carrageenan-induced pleurisy model. We found that treatment with APCP (400 $\mu \mathrm{g} /$ rat) significantly increased cell accumulation, exudate formation, and pro-inflammatory cytokine content into the pleural cavity in the acute phase $(4 \mathrm{~h})$ of inflammation, with no differences in the sub-acute phase (72 h) except for the regulation of monocyte chemotactic protein-1 levels. In addition, cells collected by pleural lavage fluids of APCPtreated rats, $4 \mathrm{~h}$ following carrageenan injection, showed increased ability to migrate in vitro, both in presence and in absence of $\mathrm{N}$-formyl-L-methionyl-L-leucyl-L-phenylalanine as chemotactic stimulus, compared to cells obtained by control rats. Our results demonstrate that APCP exacerbates the early phase of carrageenan-induced pleurisy by controlling pleural effusion and polymorphonuclear migration in vivo and ex vivo. This effect is likely dependent upon CD73 inhibition, although an inhibitory effect of other ectoenzymes cannot be ruled out.

Keywords: adenosine, CD73, ecto-5'-nucleotidase, inflammation, pleurisy, rat

\section{INTRODUCTION}

Ecto-5'-nucleotidase (ecto-5'NT/CD73), the key enzyme in leading to adenosine accumulation, has been localized on barrier cell types, such as endothelial cells, and participates in the control of barrier permeability. Thompson and coworkers (2004) by performing experiments on genetically modified mice, lacking CD73, were the first to demonstrate the important role for this ectoenzyme in the control of the vascular leakage following hypoxia, a common feature of inflamed tissues. This finding was in agreement with previous experimental work demonstrating that following hypoxia the increased CD73 activity and extracellular adenosine accumulation represent 
a protection preserving intestinal epithelium from vascular leakage. On the other hand, administration to mice of the CD73 inhibitor $\alpha, \beta$-methylene adenosine 5 '-diphosphate (APCP) significantly increased the permeability of intestinal epithelium (Synnestvedt et al., 2002; Ledoux et al., 2003). Although CD73 has been shown to play an important role in the development of pulmonary inflammation and protection against lung injury induced by artificial ventilation in mice (Eckle et al., 2007), less is known on changes of its expression and activity on tissues and cells following inflammation. Indeed, in an inflammatory environment, recruited and stromal cells expressing CD73 are critical producers of adenosine that, in turn, by engaging its receptors on adjacent cells, exerts an immunomodulatory effect (Antonioli et al., 2013).

Pleurisy is characterized by inflammation of the pleura, the tissue composed of mesothelial cells, lining the lung and regulating pleural cavity homeostasis. Carrageenan-induced rat pleurisy is a model characterized by an early $(4 \mathrm{~h})$ and late $(72 \mathrm{~h})$ phase of inflammation, and it is a useful model to study pleural effusion, resulting in extravasation and cell accumulation into the pleural space (Murai et al., 2003) that may represent a severe complication of pulmonary and extra pulmonary diseases.

Aim of the present study was to analyze the role of CD73 in pleural effusion, in rat. We found that treatment with the CD73 inhibitor, APCP, influences the accumulation of leukocytes and cytokine production within pleural cavity. These effects were associated with worsened lung injury and enhanced ability of pleural leukocytes to migrate. All together, our data suggest that CD73 represents an endogenous modulator of pleural effusion during the early phase of inflammation.

\section{MATERIALS AND METHODS}

\section{Animals}

All experiments were performed on male Wistar rats (220-260 g; Charles River, Calco, Italy). The animals were maintained at a room temperature of $22 \pm 2^{\circ}$ on a $12 \mathrm{~h} / 12 \mathrm{~h}$ light/dark cycle and were housed in a specific pathogen-free environment and fed standard rodent chow and water ad libitum. All procedures were performed according to the Italian (DL 26/2014) and European (n.63/2010/UE) regulations on the protection of animals used for experimental and other scientific purposes and were approved by Italian Ministry of Health (Number 1039/2016).

\section{Carrageenan-Induced Pleurisy}

Rats were anesthetized with $4 \%$ enflurane mixed with $0.5 \mathrm{~L} / \mathrm{min}$ $\mathrm{O}_{2}$ and $0.5 \mathrm{~L} / \mathrm{min} \mathrm{N}_{2} \mathrm{O}$, and a skin incision at the level of the left sixth intercostal space was performed. The underlying muscle was dissected, and $0.2 \mathrm{ml}$ of $\lambda$-carrageenan type IV $(1 \% \mathrm{w} / \mathrm{v}$; Sigma-Aldrich, Milan, Italy) was injected into the pleural cavity. The CD73 inhibitor, APCP (400 $\mu \mathrm{g} / \mathrm{rat}$; Tocris Bioscience, Bristol, $\mathrm{UK}$ ), or an equal volume of the vehicle (distilled water), was injected into the pleural cavity immediately before carrageenan injection. The skin was then sutured, and animals were returned to their cages and allowed to have food and water ad libitum; 4 and $72 \mathrm{~h}$ following pleurisy induction, rats were sacrificed by
$\mathrm{CO}_{2}$ inhalation. The chest was carefully opened, and the pleural cavity was washed with $2 \mathrm{ml}$ of sterile saline containing $10 \mathrm{U} /$ $\mathrm{ml}$ heparin (Sigma-Aldrich, Milan Italy). Any lavage fluid with blood contamination was rejected. The volume of pleural lavage fluid collected from each animal was measured; then, fluids were centrifuged at $180 \times \mathrm{g}$ for $10 \mathrm{~min}$ and the pellet suspended in phosphate-buffered saline (PBS). Cells were counted with $\mathrm{TC}^{\mathrm{TM}}{ }^{\mathrm{TM}}$ Automated Cell Counter (Bio-Rad, Italy). Samples of supernatants and cell pellets were then frozen at $-80^{\circ} \mathrm{C}$ to be successively analyzed for cytokine content and AMPase activity, whereas differential cell count was performed in smears by MayGrunwald-Giemsa staining (Carlo Erba, Italy). Lung samples were harvested from each rat and immediately frozen at $-80^{\circ} \mathrm{C}$ or fixed in formaldehyde solution ( $4 \% \mathrm{v} / \mathrm{v}$, in distilled water) for 1 week at room temperature and successively utilized for further analyses.

\section{Morphological Analysis}

Morphological analysis was performed on pulmonary tissue samples from vehicle- and APCP-treated rats. Lung biopsies harvested 4 or $72 \mathrm{~h}$ following carrageenan injection and fixed in formaldehyde, as described above, were dehydrated using graded ethanol and embedded in Paraplast (Sherwood Medical, Mahwah, NJ). Tissue sections (7- $\mu \mathrm{m}$ thickness) were then deparaffinized with xylene and stained with hematoxylin and eosin (Kaltek, Padova, Italy). A minimum of five sections per animal was analyzed under direct light microscopy (original magnification X 20) and photographed by a Leica DFC320 video camera (Leica, Milan, Italy) connected to a Leica DM RB microscope by using the Leica Application Suite software V 4.1.0.

\section{AMPase Activity}

AMPase activity, evaluated as previously described (Caiazzo et al., 2016), was assessed in cells, lung samples, and cell-free pleural lavage fluids collected from rats 4 or $72 \mathrm{~h}$ following pleurisy induction, by colorimetric measurement of the inorganic phosphate $(\mathrm{P} i)$ released following incubation with the substrate, as described by Nedeljkovic et al. (2006). Cell pellets were suspended in $50 \mu \mathrm{l}$ of ice-cold lysis buffer [4-[2-hydroxyethyl]-1-piperazine ethane sulfonic acid (HEPES), $200 \mathrm{mM} ; \mathrm{NaCl}, 400 \mathrm{mM}$; dithiothreitol (DTT), 1 mM; IGEPAL, 1\%; glycerol, 20\% (Carlo Erba, Italy), plus the protease inhibitor cocktail (Roche, Italy)] and maintained in constant agitation for $45 \mathrm{~min}$ at $4^{\circ} \mathrm{C}$. Lung tissue was transferred into a tube preloaded with one $(6.35 \mathrm{~mm})$ diameter zirconium oxide coated ceramic grinding sphere in ice-cold lysis buffer [Tris$\mathrm{HCl}, 50 \mathrm{mM} \mathrm{pH} 7.5 ; \mathrm{NaCl}, 150 \mathrm{mM}$; sodium orthovanadate, $1 \mathrm{mM} ; \beta$ glycerophosphate, $20 \mathrm{mM}$; ethylenediaminetetraacetic acid (EDTA), $2 \mathrm{mM}$; phenylmethylsulfonyl fluoride (PMSF), $1 \mathrm{mM}$; leupeptin, $5 \mu \mathrm{g} / \mathrm{ml}$; aprotinin, $5 \mu \mathrm{g} / \mathrm{ml}$; pepstatin, $5 \mu \mathrm{g} / \mathrm{ml}$; ICN Pharmaceuticals, Italy] and put into a FastPrep ${ }^{\circledR}-24$ homogenizer (MP Biomedicals, Santa Ana, California, USA) for lysis. Cell lysates and lung homogenates were then centrifuged for $15 \mathrm{~min}$ at $8,000 \times \mathrm{g}$ at $4^{\circ} \mathrm{C}$, and the supernatant (protein extract) was collected and stored at $-80^{\circ} \mathrm{C}$ until analysis. To initiate the enzymatic reaction, samples ( $50 \mu \mathrm{g}$ of proteins) were incubated with $200 \mu \mathrm{l}$ of medium containing $\mathrm{MgCl}_{2}(10 \mathrm{mM}), \mathrm{NaCl}(120 \mathrm{mM})$, 
$\mathrm{KCl}$ (5 mM), glucose (60 mM), Tris- $\mathrm{HCl}(50 \mathrm{mM})$, and $\mathrm{pH}$ 7.4. After $10 \mathrm{~min}$, AMP (2 mM) was added as substrate and samples kept at $37^{\circ} \mathrm{C}$ for $40 \mathrm{~min}$. The reaction was then stopped by the addition of trichloroacetic acid (final concentration 5\% w/v). Following sample centrifugation at $500 \times \mathrm{g}$ for $10 \mathrm{~min}$, at $37^{\circ} \mathrm{C}$, the release of $\mathrm{P} i$ was measured using Malachite Green Phosphate Assay Kit (ScienCell, Research Laboratories, Carlsbad, USA) and $\mathrm{KH}_{2} \mathrm{PO}_{4}$ as standard (Chan et al., 1986). To have the net value of $\mathrm{P} i$ produced following enzymatic reaction, aspecific $P i$ released in the absence of AMP in each sample was evaluated and the value obtained was subtracted from the value obtained following incubation with AMP. Protein concentration was measured by Bradford assay, and results were expressed as $\mathrm{P} i$ released $(\mathrm{pmol} / \mathrm{min} / \mu \mathrm{g}$ protein). AMPase activity was also assessed in cell-free pleural lavage fluids collected from rats 4 and $72 \mathrm{~h}$ following pleurisy induction by performing the same procedure described above.

\section{Cytokine Measurement}

In the pleural lavage fluids collected 4 and $72 \mathrm{~h}$ following carrageenan injection, levels of tumor necrosis factor- $\alpha$ (TNF- $\alpha$ ), interleukin-1 $\beta$ (IL-1 $\beta$ ), interleukin-6 (IL-6), and monocyte chemotactic protein-1 (MCP-1) were evaluated by a colorimetric commercial enzyme-linked immunosorbent assay (ELISA) kit (R\&D Systems, Minneapolis, MN) according to the manufacturer's instructions and expressed as pg per ml.

\section{Chemotaxis Assay}

Chemotaxis was evaluated on cells obtained from pleural lavage fluids collected $4 \mathrm{~h}$ after carrageenan injection in a 48 -well modified Boyden chamber (AP48, Neuro Probe, USA). Briefly, $2.50 \times 10^{5}$ cells in Roswell Park Memorial Institute (RPMI-1640) medium containing $0.1 \%$ bovine serum albumin (BSA) $(50 \mu \mathrm{l})$ were placed on top of the polycarbonate filter $(8-\mu \mathrm{m}$ pore size, Neuro Probe, USA) whereas $25 \mu \mathrm{l}$ of chemoattractant N-formyl-L-methionylL-leucyl-L-phenylalanine (fMLP, $1 \mathrm{ng} / \mathrm{ml}$ in RPMI-1640 medium containing $0.1 \%$ BSA) were added to the wells on the bottom. Spontaneous migration was determined using RPMI-1640 medium without fMLP. Each condition was set up in triplicate. Chambers were incubated for $90 \mathrm{~min}$ at $37^{\circ} \mathrm{C}$ in humidified air containing $5 \% \mathrm{CO}_{2}$. Following incubation, the chamber was disassembled and the filter was carefully removed and washed with sterile PBS. Cells that failed to migrate through the filter were wiped off the top surface of the filter. Migrated cells on the filter were fixed and stained with 4,6-diamidino-2-phenylindole (DAPI, Vector Laboratories, Burlingame, ON, Canada), and migration was quantified as the total pixel count of DAPI-stained nuclei under the fluorescence microscope using Fiji software. Migration index of cells obtained from pleural lavage fluids, harvested from vehicle- and APCP-treated rats, was expressed as ratio between the number of migrated cells in presence of fMLP and the number of migrated cells in the absence of fMLP.

\section{Flow Cytometry}

Pleural lavage fluids recovered from the pleural cavity were washed twice in saline, and the resulting suspensions were pelleted by centrifugation at $180 \times \mathrm{g}$ for $10 \mathrm{~min}$ at $4^{\circ} \mathrm{C}$. To block non-specific Fc-mediated interactions, cell samples were preincubated with an FcR blocking reagent (BD Biosciences) on ice for $10 \mathrm{~min}$ and then incubated with the following antibodies against: CD11b/c-PerCP/Cy5.5 (clone OX-42, BioLegend), RP-1-PE (BD Pharmingen), CD68-FITC (clone ED1, GeneTex), and CD73-Alexa Fluor 647 (Bioss Antibodies) for $20 \mathrm{~min}$ in the dark. Data were acquired with a FACSCalibur flow cytometer and analyzed with CellQuest software (BD FACSCalibur, Milan, Italy).

\section{Statistical Analysis}

All data are presented as mean \pm standard error (SE); statistical analysis was performed on raw data by two tailed Student's t-test for unpaired data or by one-way ANOVA followed by Bonferroni post-hoc test as appropriate. A p value $<0.05$ was considered statistically significant.

\section{RESULTS}

\section{APCP Treatment Increases Pleural Effusion and Cell Infiltration}

Treatment of rats with CD73 inhibitor, APCP (400 $\mu \mathrm{g} / \mathrm{rat})$, significantly increased cell accumulation into the pleural cavity $4 \mathrm{~h}$ following carrageenan injection compared to vehicle (Figure 1A), while the leukocyte number into the pleural lavage fluids collected at $72 \mathrm{~h}$ after carrageenan injection was similar in APCP- and vehicle-treated rats (Figure 1A). The volume of exudate collected by pleural lavage $4 \mathrm{~h}$ following carrageenan injection significantly increased in APCP-treated rats compared with control (vehicle-treated) rats (Figure 1B). There was no difference in the volume of exudate produced at $72 \mathrm{~h}$ after carrageenan injection between APCP- and vehicle-treated rats (Figure 1B).

\section{APCP Treatment Increases Lung Damage}

Morphological analysis of inflamed lung sections showed cell infiltration into bronchial and perivascular space as well as lung injury (Figure 2). The increased inflammatory cell infiltration in APCP-treated rats was associated with damaged lung architecture 4 and $72 \mathrm{~h}$ following carrageenan-induced pleurisy (Figure 2).

\section{APCP Treatment Is Associated With Reduced AMPase Activity}

In APCP-treated rats, the AMPase activity in cell lysates, in lung homogenates, and in cell-free pleural lavage fluids $4 \mathrm{~h}$ following carrageenan injection was significantly reduced compared with vehicle, but not at $72 \mathrm{~h}$ (Figures $\mathbf{3 A}, \mathbf{B}$, and $\mathbf{C}$, respectively). It is worth noting that the AMPase activity in cell lysates at $72 \mathrm{~h}$ was higher than at $4 \mathrm{~h}$ (Figure 3A) and in cell-free pleural lavage fluids was lower at $72 \mathrm{~h}$ than at $4 \mathrm{~h}$ (Figure 3C). In lung homogenates, there was no difference in AMPase activity between 4 and $72 \mathrm{~h}$ (Figure 3B). 
A

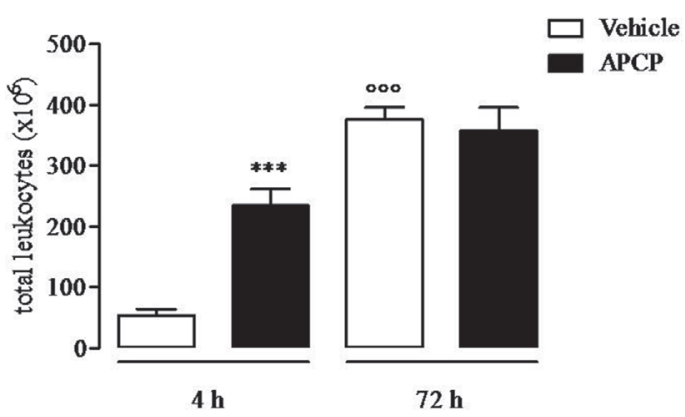

B

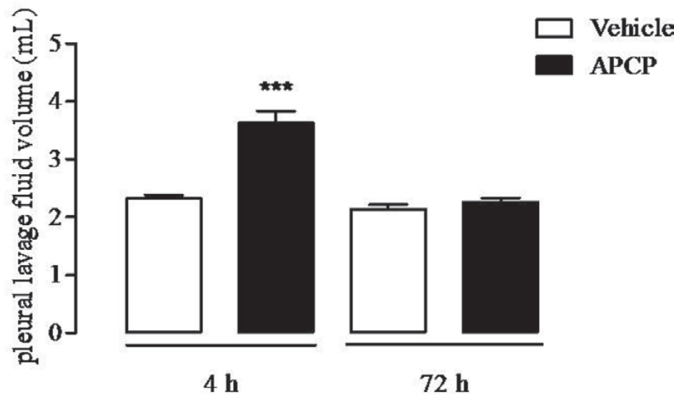

FIGURE 1 | Effect of APCP on leukocyte infiltration and pleural lavage fluid volume 4 and $72 \mathrm{~h}$ following carrageenan-induced rat pleurisy. (A) Total leukocytes. (B) Pleural lavage fluid volume. Data are expressed as mean $\pm \mathrm{SE}, \mathrm{N}=10$; (A) ${ }^{\star \star \star} \mathrm{p}<0.001$ and ${ }^{000} \mathrm{p}<0.001$ versus vehicle $4 \mathrm{~h}$. (B) ${ }^{\star \star \star} \mathrm{p}<0.001$ versus vehicle $4 \mathrm{~h}$. Two-tailed Student's t-test.
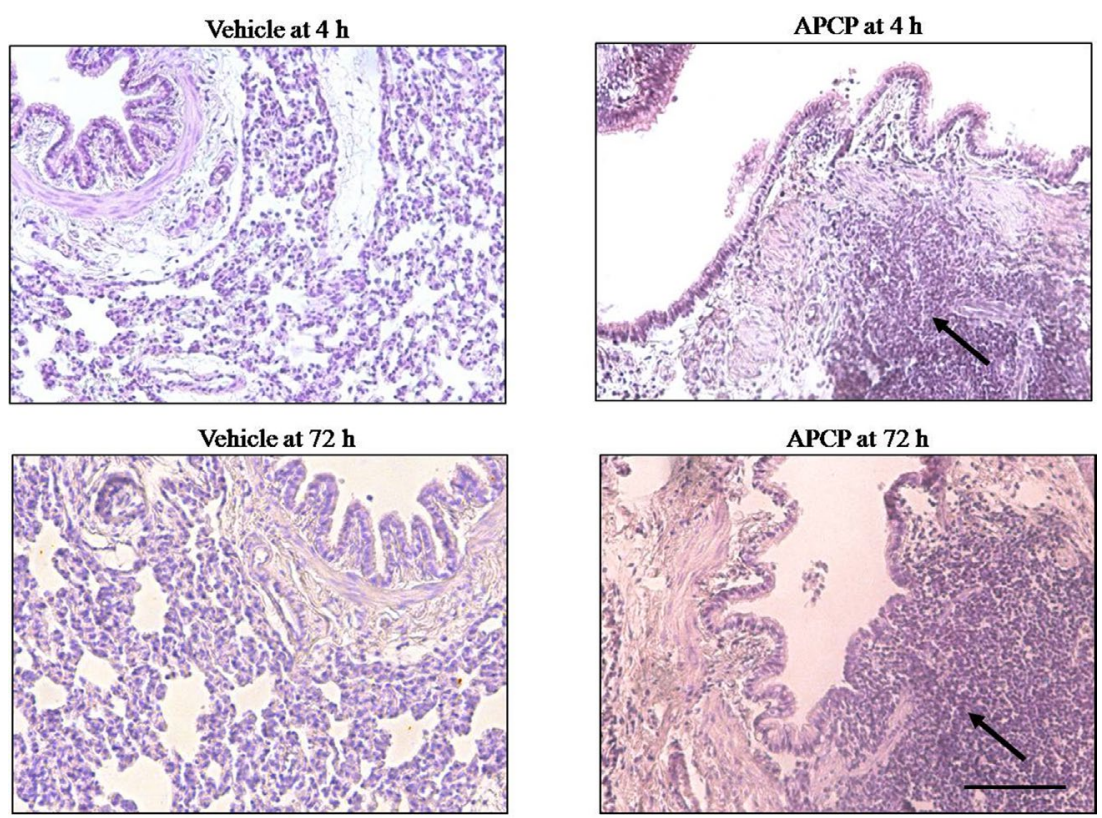

FIGURE 2 | Effect of APCP on lung injury 4 and $72 \mathrm{~h}$ following carrageenan-induced pleurisy. Representative morphological analysis of hematoxylin and eosin (H\&E)-stained lung sections from vehicle group ( 4 and $72 \mathrm{~h}$ ) and APCP group (4 and $72 \mathrm{~h}$ ). Black arrows indicate points of intense inflammatory cell infiltration. Original magnification $\times 20$. Scale bar $=100 \mu \mathrm{m}$.

\section{APCP Treatment Increases Cytokine Production in Pleural Fluids}

Following treatment with APCP, there was a significant increase in TNF- $\alpha$, IL-6, IL-1 $\beta$, and MCP-1 levels evaluated in cell-free pleural lavage fluids collected $4 \mathrm{~h}$ following pleurisy induction (Figures 4A, B, C, and D, respectively). In contrast, TNF- $\alpha$, IL-6, and IL-1 $\beta$ levels in pleural lavage fluids collected at $72 \mathrm{~h}$ were similar in APCP- and vehicle-treated rats (Figures 4A, B, and $\mathbf{C}$, respectively), while MCP-1 levels were still significantly increased in APCP-treated rats compared with control (vehicletreated) at $72 \mathrm{~h}$ (Figure 4D).

\section{APCP Treatment Increases PMN Migration Index}

Cells obtained from pleural lavage fluids collected from APCP-treated group of rats $4 \mathrm{~h}$ after carrageenan injection showed increased ability to migrate in vitro both in presence and in absence of a chemotactic stimulus (fMLP), compared to cells from vehicle groups, as showed in the representative images of Figure 5A. Accordingly, the migration index was significantly increased in samples from APCP-treated rats compared with control (vehicle-treated rats) in presence of fMLP (Figure 5B). 

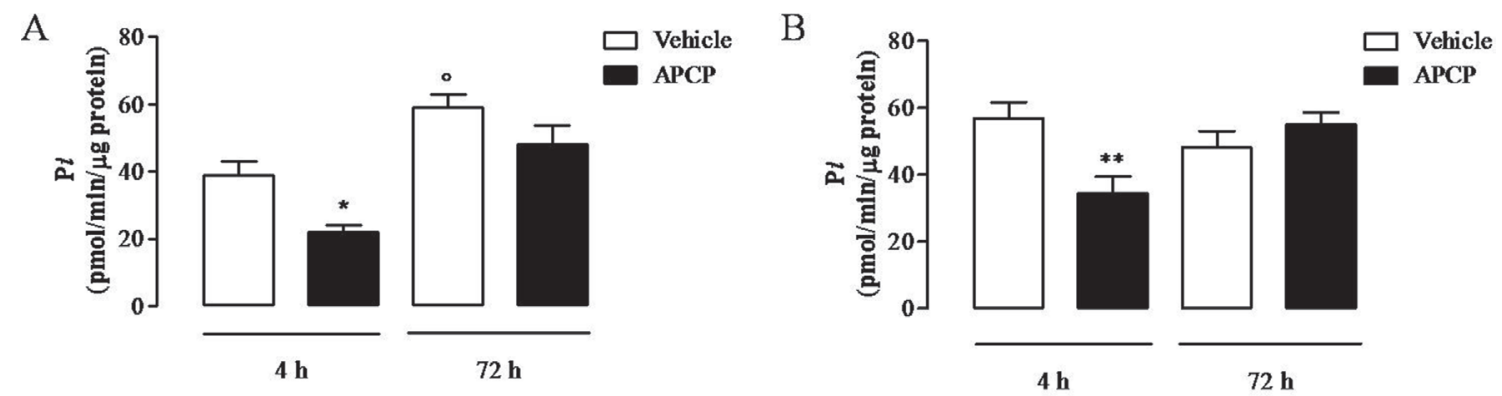

C

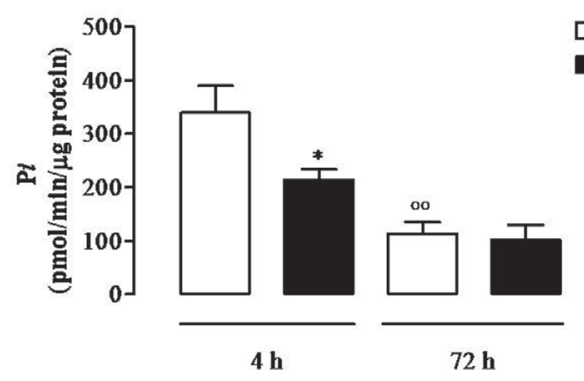

FIGURE 3 | AMPase activity in cells (A), lungs (B), and pleural lavage fluids (C) collected 4 and $72 \mathrm{~h}$ following carrageenan-induced pleurisy. Data are expressed as mean \pm SE, $N=6$; (A) ${ }^{*} p<0.05$ and ${ }^{\circ} p<0.05$ versus vehicle $4 \mathrm{~h}$. (B) ${ }^{* *} p<0.01$ versus vehicle $4 \mathrm{~h}$. (C) ${ }^{*} \mathrm{p}<0.05$ and ${ }^{\circ 0} \mathrm{p}<0.01$ versus vehicle $4 \mathrm{~h}$. Bonferroni's multiple comparison test.

A

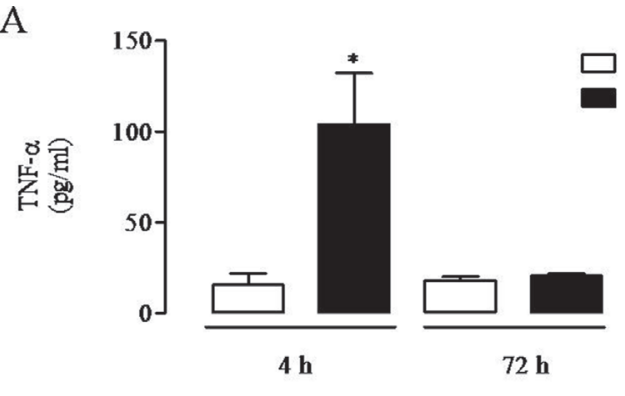

C

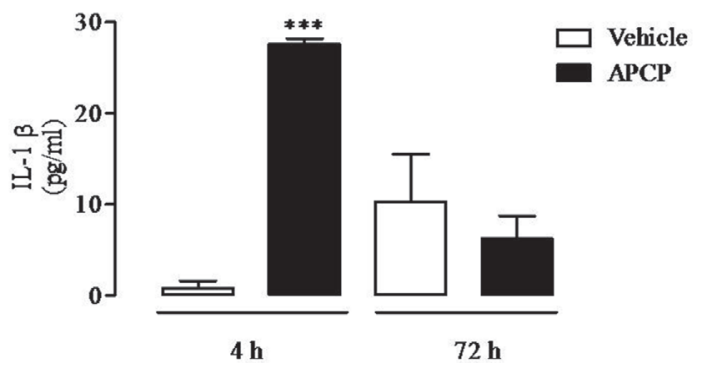

$\mathrm{B}$

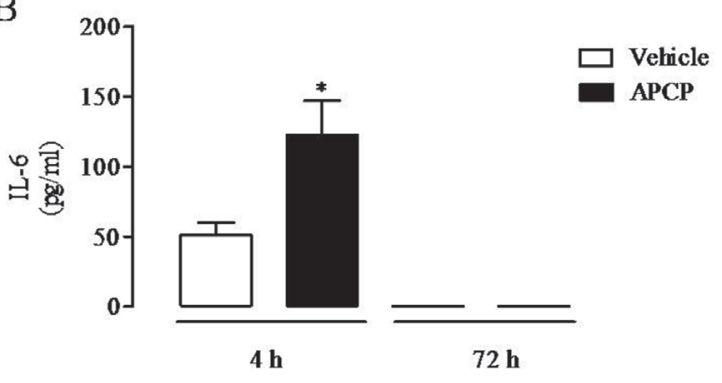

D

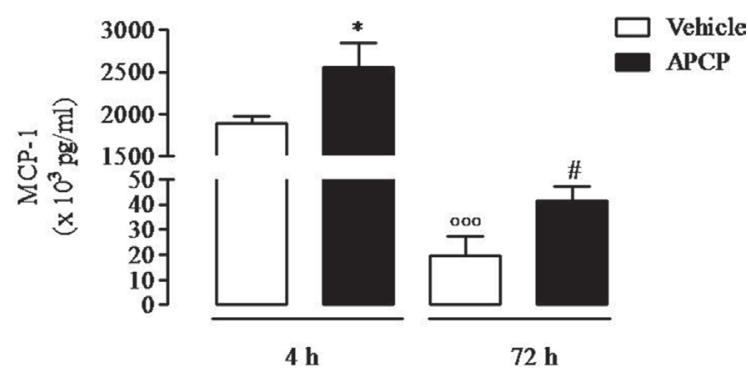

FIGURE 4 | Effect of APCP on levels of TNF- $\alpha$ (A), IL-6 (B), IL-1 $\beta$ (C), and MCP-1 (D) in pleural lavage fluid recovered from the pleural cavity 4 and $72 \mathrm{~h}$ following carrageenan-induced rat pleurisy. Data are expressed as mean $\pm \mathrm{SE}, \mathrm{N}=6$; (A) ${ }^{*} \mathrm{p}<0.05$ versus vehicle $4 \mathrm{~h}$. (B) ${ }^{*} \mathrm{p}<0.05$ versus vehicle $4 \mathrm{~h}$. (C) ${ }^{\star \star \star} \mathrm{p}<0.001$ versus vehicle 4 h. (D) ${ }^{\star} p<0.05$ and ${ }^{000} p<0.001$ versus vehicle $4 \mathrm{~h}$; $\mathrm{p} p<0.05$ versus vehicle $72 \mathrm{~h}$. Two-tailed Student's t-test. 
A

\section{+ fMLP}

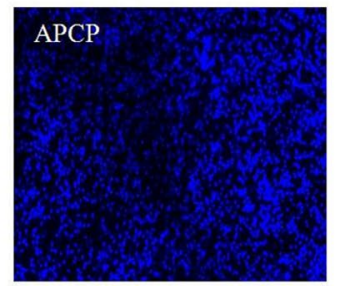

+ fMLP

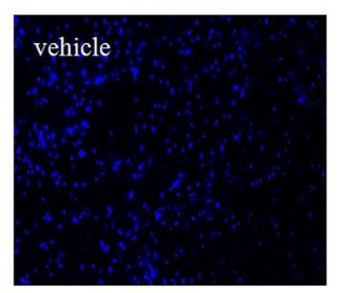

- fMLP

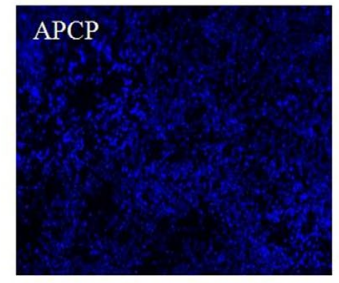

- fMLP

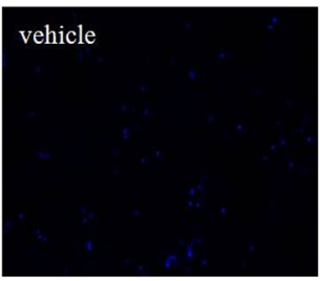

B

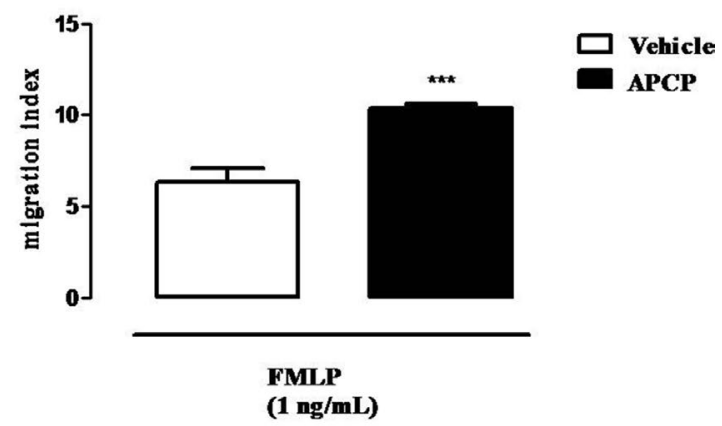

FIGURE 5 | Effect of APCP on chemotaxis of leukocytes collected 4 h after carrageenan injection. (A) Representative immunofluorescence showing DAPI-stained nuclei from vehicle and APCP-treated group; cell chemotaxis was evaluated in presence and in absence of fMLP (see text for details). Original magnification X 10. (B) Histogram representing the results of migration index expressed as ratio between the number of migrated cells in presence of fMLP and the number of migrated cells without $\mathrm{fMLP}$. Cells were collected from pleural lavage fluids harvested from vehicle- and APCP-treated rats. Data are expressed as mean $\pm \mathrm{SE}, \mathrm{N}=8$. ${ }^{* \star \star} \mathrm{p}<$ 0.001 versus vehicle. Two-tailed Student's t-test.

\section{Leukocyte Populations into the Pleural Cavity}

Differential cell count of leukocytes migrated into the pleural cavity showed that PMN neutrophils dominated the early phase $(4 \mathrm{~h}$ ) of the reaction and were replaced by monocytes at $72 \mathrm{~h}$ (data not shown). To assay neutrophil and monocyte cell subsets and the expression of CD73, cells collected from pleural lavage fluids at 4 and $72 \mathrm{~h}$ following pleurisy induction were analyzed by flow cytometry. Cells collected at 4 hours were mostly neutrophils (CD11b/c $/ \mathrm{c}^{+} \mathrm{P}-1^{+}$cells) with no difference from APCP- and vehicle-treated group (Figure 6A). Moreover, the percentage of $\mathrm{CD}^{2} 3^{+}$cells among them $\left(\mathrm{CD} 11 \mathrm{~b} / \mathrm{c}^{+} \mathrm{RP}-1^{+} \mathrm{CD} 73^{+}\right)$was very low in both groups (Figure 6A). Flow cytometric analysis of cells collected at $72 \mathrm{~h}$ showed that the main population within leucocytes were represented by monocytes/macrophages $\left(\mathrm{CD} 11 \mathrm{~b} / \mathrm{c}^{+} \mathrm{CD} 68^{+}\right.$cells $)$that were significantly reduced in pleural fluids harvested from APCP-treated rats compared with those from vehicle-treated rats (Figure 6B). In both vehicle- and APCP-treated groups, these cells were positive to CD73 (CD11b/ $\mathrm{C}^{+} \mathrm{CD} 68^{+} \mathrm{CD} 73^{+}$cells) (Figure 6B). It is worth noting that another subset of cells, CD11b/c $\mathrm{c}^{+} \mathrm{CD} 68$, represented about $40 \%$ of cells harvested at $72 \mathrm{~h}$.

\section{DISCUSSION}

There is much evidence for the role of CD73 in maintenance the integrity of epithelial barrier (Narravula et al., 2000; Salmi and Jalkanen, 2005; Bowser and Broaddus, 2016). Early papers investigating the involvement of CD73 in physiopathological conditions found that this enzyme was an innate protection in lung injury (Eckle et al., 2007). Pleural mesothelium is a monolayer of mesothelial cells lining the pleural cavity, presenting intermediate features between epithelium and endothelium; mesothelial cells participate to the pleural space homeostasis and represent the primary cells that initiate the response to an injury (Mutsaers, 2004; Batra and Antony, 2015).

Injection of carrageenan into the rat pleural cavity elicits an inflammatory response characterized by pleural effusion that dominates the early phase $(4 \mathrm{~h})$, characterized by cell recruitment, mostly PMNs, cytokine production, and tissue morphological changes. The model may resemble human pleural effusion, a severe complication often associated to pulmonary and extra pulmonary pathologies (Vinegar et al., 1982; De Brito, 1989; Murai et al., 2003; Lansley et al., 2017). Here, we have evaluated the effect of APCP, a CD73 inhibitor, in the inflammatory response triggered by carrageenan, in the model of rat pleurisy.

Following rat treatment with APCP, we found increased pleural effusion and total cell accumulation into the pleural cavity, in response to carrageenan injection, $4 \mathrm{~h}$ thereafter. At the same time point, the increased cell infiltration was paralleled by increased cytokine levels (IL-6, TNF alpha, IL-1 beta, MCP-1) into the pleural cavity. Conversely, in the pleural lavage fluids collected $72 \mathrm{~h}$ following injection of carrageenan, cytokine levels were almost absent in agreement with evidence of their early involvement in this model of inflammation (Goodman et al., 1993; Murai et al., 2003). Furthermore, at 72 h, there was no difference in cellular and cytokine content between vehicle- and APCP-treated group, apart from MCP-1 whose levels in APCP group were still higher than those in vehicle group.

It is known that MCP-1 represents a chemokine that, in the pleural space, is produced by mesothelial and inflammatory 

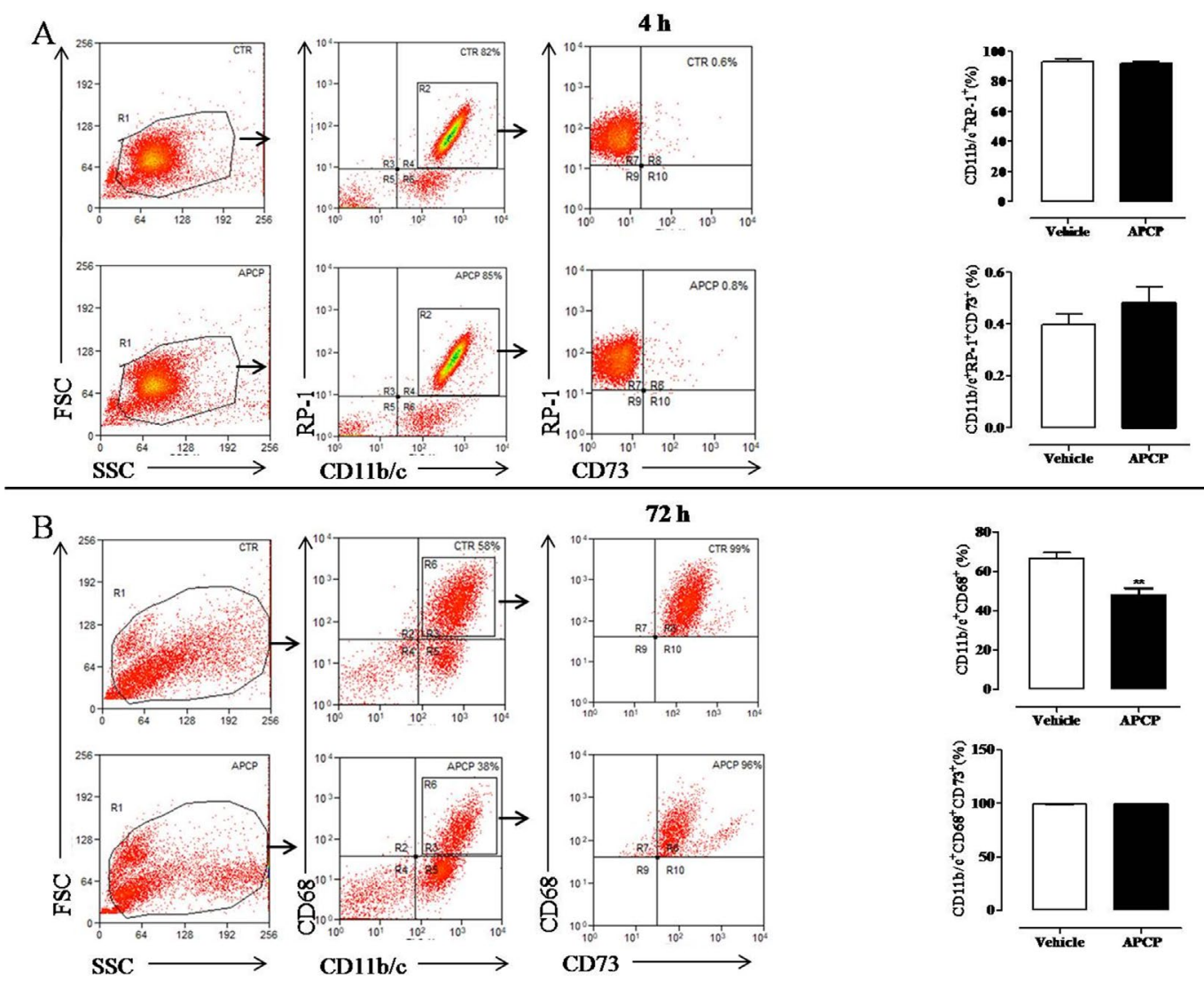

FIGURE 6 | Analysis of CD73 expression on leukocyte subpopulations recovered from the pleural cavity at $4 \mathrm{~h}$ (A) and $72 \mathrm{~h}$ (B) after carrageenan injection. Flow cytometry dot plots in panel A (left) show a representative experiment illustrating the gating strategy used to analyze CD11b/c positive ${ }^{(+)}$RP-1 positive ${ }^{(+)}$cells gated

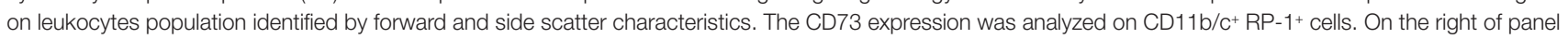
A, histograms summarize the percentage of cells positive to CD11b/c and RP-1 and the percentage of CD73 positive cells among CD11b/ $\mathrm{C}^{+} \mathrm{RP}-1^{+}$cells in vehicle

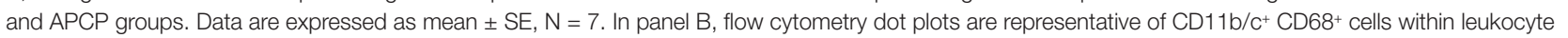
population identified by forward and side scatter characteristics. CD11b/ $\mathrm{C}^{+} \mathrm{CD} 68^{+}$cells were then analyzed for their CD73 expression. On the right of panel B, histograms summarize the percentage of cells positive to CD11b/c and CD68 and the percentage of CD73 positive cells among CD11b/ $\mathrm{C}^{+}$CD68 ${ }^{+}$cells in vehicle and APCP groups. Results represent mean $\pm \mathrm{SE}, \mathrm{N}=7$. ${ }^{* *} \mathrm{p}<0.01$. Two-tailed Student's t-test.

cells (Deshmane et al., 2009; Batra and Antony, 2015). Recently, Lansley et al. (2017) have demonstrated that MCP-1 plays a crucial role in pleural effusion in a mouse model of carrageenaninduced pleurisy. Here, we show that MCP-1 is the cytokine that prevails in pleural lavage fluids at 4 and $72 \mathrm{~h}$ following carrageenan injection in rats; moreover, our results suggest that MCP-1 production is under the control of CD73. The role of CD73 in the control of neutrophil influx in response to inflammation and infections has also demonstrated in experiments performed in transgenic mice lacking CD73 enzyme, in which following Mycobacterium tubercolosis infection, an increased influx of PMNs but not of monocytes has been observed (Petit-Jentreau et al., 2015). Consistently, we found that treatment with APCP at the onset of inflammation affects the early phase $(4 \mathrm{~h})$, dominated by neutrophil influx, but not the sub-acute phase $(72 \mathrm{~h})$ of inflammation, dominated by monocyte influx. APCP is a well described CD73 inhibitor; however, there is evidence that this compound also inhibits human nucleotide pyrophosphatase/ phosphodiesterases (NPPs), a related nucleotidase hydrolizing
ATP or ADP to AMP although with very low potency (Bhattarai et al., 2015). NPP is also involved in the adenosine pathway recognized as non-canonical, leading to adenosine accumulation from ATP and NAD (Ferrero et al., 2019). Furthermore, there is evidence that APCP through increasing AMP levels may indirectly inhibit NTPDase (CD39) (Covarrubias et al., 2016). Nonetheless, what we have found is that treatment with APCP exacerbates carrageenan-induced pleurisy in rats; we claim that to this effect contributes the inhibition of CD73, and probably of the other enzymes involved in the adenosinergic pathway, with the resulting loss of the control that these ectoenzymes exert on the inflammatory environment. Thus, CD73, or more extensively the adenosinergic pathway, results to be critical for PMN trafficking in the model of carrageenan-induced pleurisy in rat. Similarly, it has been demonstrated that CD73 controls PMN trafficking in lung injury induced by bacterial lipopolysaccharide inhalation in mice (Reutershan et al., 2009).

We also attempted to analyze cells collected at $4 \mathrm{~h}$, to evaluate how they behaved far from the inflammatory microenvironment. 
For this purpose, we evaluated cell migration ex vivo, in presence or not of fMLP as chemoattractant agent. Interestingly, we found that PMNs collected from APCP-treated animals showed increased ability to migrate, even spontaneously, in absence of fMLP, compared to cells obtained from vehicle group. These results suggest that early inhibition of CD73 makes inflammatory cells, mostly neutrophils, prone to migrating. Likely, this effect may depend upon a contact with elevated levels of cytokines of cells obtained from APCP-treated animals compared to cells obtained from inflamed vehicle-treated animals. Alternatively, we might hypothesize that when CD73 is inhibited, a phenotypically different neutrophil population accumulates at the site of inflammation.

Neutrophil heterogeneity has been described (Scapini et al., 2016), and it is known that their differentiation toward distinct subpopulations depends upon environmental signals and also their lifespan (Silvestre-Roig et al., 2016). It is known that CD73 expression on neutrophils is normally low, and it's under the control of inflammatory cytokines (Szabo and Pacher, 2012; Antonioli et al., 2013). By performing flow cytometric analysis of cells accumulated into the pleural space, we found that only a very small percentage of all leukocytes accumulated $4 \mathrm{~h}$ following carrageenan injections were $\mathrm{CD}^{+} 3^{+}$, conversely, almost the totality of leukocytes accumulated at $72 \mathrm{~h}$ were $\mathrm{CD} 3^{+}$, and there was no difference in the percentage of cells $\mathrm{CD}^{2} 3^{+}$between vehicle- and APCP-treated group. Nonetheless, there was difference in AMPase activity between cells obtained from the two groups, being the activity of cells recovered from pleural lavage fluid of APCP-treated rats significantly lower than AMPase activity of cells from vehicle-treated group. All together, these results suggest that cell trafficking into the pleural space is regulated by CD73 enzymatic activity. Our data agree with previous experimental results, in mice, and clinical data that highlight the important regulatory role of CD73 in the control of cell trafficking and cytokine production in an inflammatory environment (Reutershan et al., 2009; Petrovic-Djergovic et al., 2012; Al-Taei et al., 2016).

However, to better understand the mechanism by which CD73/adenosine pathway controls the inflammatory reaction in our model, we need to establish which cells are targeted by APCP. Indeed, we found that the effect of rat treatment with APCP was evident at 4 hours, when only a very small subset of infiltrating cells were $\mathrm{CD}^{+} 3^{+}$; thus, it is conceivable that APCP does not exert its effect on recruited cells but on stromal cells and/or on other type of cells, such as dendritic cells, representing a first line

\section{REFERENCES}

Al-Taei, S., Salimu, J., Spary, L. K., Clayton, A., Lester, J. F., and Tabi, Z. (2016). Prostaglandin E(2)-mediated adenosinergic effects on CD14(+) cells: selfamplifying immunosuppression in cancer. Oncoimmunology 6, e1268308. doi: 10.1080/2162402X.2016.1268308

Antonioli, L., Pacher, P., Vizi, E. S., and Haskó, G. (2013). CD39 and CD73 in immunity and inflammation. Trends Mol. Med. 19, 355-367. doi: 10.1016/j. molmed.2013.03.005

Batra, H., and Antony, V. B. (2015). Pleural mesothelial cells in pleural and lung diseases. J. Thorac. Dis. 7, 964-980. doi: 10.3978/j.issn.2072-1439.2015.02.19 of host defense and demonstrating to infiltrate the pleural space (Condon et al., 2011). It is known that dendritic cells expressing both CD39 and CD73 transform a proinflammatory ATP-rich microenvironment into an antinflammatory adenosine rich environment (Silva-Vilches et al., 2018). Unfortunately, we did not sort dendritic cells by flow cytometry; nonetheless, it can be argued that subset of cells $\mathrm{CD} 11 \mathrm{~b} / \mathrm{c}^{+} \mathrm{CD} 68^{-}$found at 72 hours are dendritic cells; however, this point needs to be further investigated.

In conclusion, rat treatment with APCP exacerbates the early phase of inflammation by controlling pleural effusion and polymorphonuclear migration in vivo and ex vivo. Although we cannot rule out the possibility that APCP inhibits other ectoenzymes involved in the adenosinergic pathway, we argue that CD73 inhibition might play a major role. On this basis, we suggest that CD73 might represent a valid biomarker for pleural effusion besides being a potential target for novel therapeutic interventions.

\section{DATA AVAILABILITY}

The datasets generated for this study are available on request to the corresponding author.

\section{ETHICS STATEMENT}

All procedures were performed according to the Italian and European regulations (DL 26/2014) on the protection of animals used for experimental and other scientific purposes and were approved by Italian Ministry of Health.

\section{AUTHOR CONTRIBUTIONS}

EC, SM, and CC contributed to the study design, study conduct, and data analysis. EC and CC contributed to the data collection, data interpretation and drafting of the manuscript. EC, RC, AI, and $\mathrm{CC}$ revised the manuscript.

\section{FUNDING}

This work was supported by the grant of University of Naples Federico II (Research Program 2017-2019; DR 409 del 7 Febbraio 2017). 
Chan, K. M., Delfert, D., and Junger, K. D. (1986). A direct colorimetric assay for Ca2+-stimulated ATPase activity. Anal. Biochem. 157, 375-380. doi: 10.1016/0003-2697(86)90640-8

Condon, T. V., Sawyer, R. T., Fenton, M. J., and Riches, D. W. (2011). Lung dendritic cells at the innate-adaptive immune interface. J. Leukoc. Biol. 90, 883-895. doi: 10.1189/jlb.0311134

Covarrubias, R., Chepurko, E., Reynolds, A., Huttinger, Z. M., Huttinger, R., Stanfill, K., et al. (2016). Role of the CD39/CD73 purinergic pathway in modulating arterial thrombosis in mice. Arterioscler. Thromb. Vasc. Biol. 36, 1809-1820. doi: 10.1161/ATVBAHA.116.307374

De Brito, F. B. (1989). "Pleurisy and pouch models of acute inflammation," in Pharmacological Methods in the Control of Inflammation. Alan R. Liss. Inc. pp. 173-228.

Deshmane, S. L., Kremlev, S., Amini, S., and Sawaya, B. E. (2009). Monocyte chemoattractant protein-1(MCP-1): an overview. J. Interferon Cytokine Res. 29, 313-326. doi: 10.1089/jir.2008.0027

Eckle, T., Füllbier, L., Wehrmann, M., Khoury, J., Mittelbronn, M., Ibla, J., et al. (2007). Identification of ectonucleotidases CD39 and CD73 in innate protection during acute lung injury. J. Immunol. 178, 8127-8137. doi: 10.4049/jimmunol.178.12.8127

Ferrero, E., Faini, A. C., and Malavasi, F. (2019). A phylogenetic view of the leukocyte ectonucleotidases. Immunol. Lett. 205, 51-58. doi: 10.1016/j.imlet.2018.06.008

Goodman, R., Mantegna, L. R., McAilister, C. L., Bruin, E., Dowling, R. L., George, H., et al. (1993). IL-1 and its role in rat carrageenan pleurisy. Mediators Inflamm. 2, 33-39. doi: 10.1155/S0962935193000043

Lansley, S. M., Cheah, H. M., and Lee, Y. C. (2017). Role of MCP-1 in pleural effusion development in a carrageenan-induced murine model of pleurisy. Respirology 22, 758-763. doi: 10.1111/resp.12951

Ledoux, S., Runembert, I., Koumanov, K., Michel, J. B., Trugnan, G., and Friedlander, G. (2003). Hypoxia enhances Ecto-5'-Nucleotidase activity and cell surface expression in endothelial cells: role of membrane lipids. Circ. Res. 92, 848-855. doi: 10.1161/01.RES.0000069022.95401.FE

Murai, N., Nagai, K., Fujisawa, H., Hatanaka, K., Kawamura, M., and Harada, Y. (2003). Concurrent evolution and resolution in an acute inflammatory model of rat carrageenan - induced pleurisy. J. Leukoc. Biol. 73, 456-463. doi: 10.1189/ jlb.1002502

Mutsaers, S. E. (2004). The mesothelial cell. Int. J. Biochem. Cell. Biol. 36, 9-16. doi: 10.1016/S1357-2725(03)00242-5

Narravula, S., Lennon, P. F., Mueller, B. U., and Colgan, S. P. (2000). Regulation of endothelial CD73 by adenosine: paracrine pathway for enhanced endothelial barrier function. J. Immunol. 165, 5262-5268. doi: 10.4049/jimmunol.165.9.5262

Nedeljkovic, I., Ostojic, M., Beleslin, B., Djordjevic-Dikic, A., Stepanovic, J., Nedeljkovic, M., et al. (2006). Comparison of exercise, dobutamine-atropine and dipyridamole-atropine stress echocardiography in detecting coronary artery disease. Cardiovasc. Ultrasound 3, 4-22. doi: 10.1186/1476-7120-4-22

Petit-Jentreau, L., Jouvion, G., Charles, P., Majlessi, L., Gicquel, B., and Tailleux, L. (2015). Ecto-5'-nucleotidase (CD73) deficiency in mycobacterium tuberculosis-infected mice enhances neutrophil recruitment. Infect. Immun. 83, 3666-3674. doi: 10.1128/IAI.00418-15

Petrovic-Djergovic, D., Hyman, M. C., Ray, J. J., Bouis, D., Visovatti, S. H., Hayasaki, T., et al. (2012). Tissue-resident ecto-5' nucleotidase (CD73) regulates leukocyte trafficking in the ischemic brain. J. Immunol. 188, 23872398. doi: 10.4049/jimmunol.1003671

Reutershan, J., Vollmer, I., Stark, S., Wagner, R., Ngamsri, K. C., and Eltzschig, H. K. (2009). Adenosine and inflammation:CD39 and CD73 are critical mediators in LPS-induced PMN trafficking into the lungs. FASEB J. 23, 473-482. doi: 10.1096/fj.08-119701

Salmi, M., and Jalkanen, S. (2005). Cell-surface enzymes in control of leukocyte trafficking. Nat. Rev. Immunol. 5, 760-771. doi: 10.1038/nri1705

Scapini, P., Marini, O., Tecchio, C., and Cassatella, M. A. (2016). Human neutrophils in the saga of cellular heterogeneity: insights and open questions. Immunol. Rev. 273, 48-60. doi: 10.1111/imr.12448

Silva-Vilches, C., Ring, S., and Mahnke, K. (2018). ATP and its metabolite adenosine as regulators of dendritic cell activity. Front. Immunol. 9, 2581. doi: 10.3389/fimmu.2018.02581

Silvestre-Roig, C., Hidalgo, A., and Soehnlein, O. (2016). Neutrophil heterogeneity: implications for homeostasis and pathogenesis. Blood 127, 2173-2181. doi: 10.1182/blood-2016-01-688887

Synnestvedt, K., Furuta, G. T., Comerford, K. M., Louis, N., Karhausen, J., Eltzschig, H. K., et al. (2002). Ecto-5'-nucleotidase (CD73) regulation by hypoxiainducible factor-1 mediates permeability changes in intestinal epithelia. J. Clin. Invest. 110, 993-1002. doi: 10.1172/JCI0215337

Szabo, C., and Pacher, P. (2012). The outsiders: emerging roles of ectonucleotidases in inflammation. Sci. Transl. Med. 4, 146ps14. doi: 10.1126/scitranslmed. 3004378

Thompson, L. F., Eltzschig, H. K., Ibla, J. C., Van De Wiele, C. J., Resta, R., MoroteGarcia, J. C., et al. (2004). Crucial role for ecto-5'-nucleotidase (CD73) in vascular leakage during hypoxia. J. Exp. Med. 200, 1395-1405. doi: 10.1084/ jem.20040915

Vinegar, R., Truax, J. F., Selph, J. L., and Voelker, F. A. (1982). Pathway of onset, development, and decay of carrageenan pleurisy in the rat. Fed. Proc. 41, 2588-2595.

Conflict of Interest Statement: The authors declare that the research was conducted in the absence of any commercial or financial relationships that could be construed as a potential conflict of interest.

Copyright (C) 2019 Caiazzo, Morello, Carnuccio, Ialenti and Cicala. This is an openaccess article distributed under the terms of the Creative Commons Attribution License (CC BY). The use, distribution or reproduction in other forums is permitted, provided the original author(s) and the copyright owner(s) are credited and that the original publication in this journal is cited, in accordance with accepted academic practice. No use, distribution or reproduction is permitted which does not comply with these terms. 